Praxis International Journal of Social Science and Literature

Impact Factor: SJIF $2020=5.754$, ISSN: 2581-6675

Vol - 4, Issue - 02, February - 2021

Website: www.pijssl.com, Email: editor.pijss1@gmail.com

\title{
महत्त्वपूर्ण अवधी कवि: लक्ष्मण प्रसाद 'मित्र'
}

\author{
शशांक मिश्र, स्वतंत्र अध्ययन एवं शोधकार्य \\ डॉ. कैलाश देवी सिंह, अवकाश प्राप्त प्रोफेसर, \\ हिंदी तथा आधुनिक भारतीय भाषा विभाग, \\ लखनऊ विश्वविद्यालय, लखनऊ
}

\section{सारांश}

विज्ञापन और आत्मश्नाघा के विस्फोटक युग में वे रचनाकार प्रायः अलक्षित-अचर्चित रह जाते हैं, जो मात्र रचने में विश्वास रखते हैं। आधुनिक अवधी कविता के महत्त्वपूर्ण किन्तु प्रायः अचर्चित कवि लक्ष्मण प्रसाद 'मित्र' इसके उदाहरण हैं। प्रायः समस्त अवधी कविता मर्मजों ने आधुनिक अवधी कविता का विश्नेषण करते हुये कविनाम परिगणन के अंतर्गत मित्र जी का स्मरण पुनः-पुनः किया है, किन्तु डॉ. श्यामसुंदर मित्र 'मधुप' के अतिरिक्त अन्य किसी ने उन्हें सोदाहरण प्रस्तुत नहीं किया है। जिन व्यक्तियों ने अवधी कविता के आधुनिक पक्ष पर शोध कार्य किया है, वे भी इस परिश्रम से मुँह चुरा गये। फलतः आज हमारे अवधी कवियों की एक दीर्घ सूची है, मगर उनके विषय में ठोस ज्ञान का नितान्त अभाव। यह सूचनात्मक ज्ञान प्रतियोगी परीक्षाओं अथवा वाद-विवाद प्रतियोगिताओं में उपयोगी हो सकता है किन्तु शोध के गंभीर क्षेत्र में इस प्रवृत्ति का निषेध होना चाहिए।

बीज शब्द: अवधी, कवि, अवध, लक्ष्मण प्रसाद ‘मित्र’, लोक-कविता, अवधी काव्य प्रवृत्ति।

\section{परिचय}

विज्ञापन और आत्मश्लाघा के विस्फोटक युग में वे रचनाकार प्रायः अलक्षित-अचर्चित रह जाते हैं, जो मात्र रचने में विश्वास रखते हैं। आधुनिक अवधी कविता के महत्त्वपूर्ण किन्तु प्रायः अचर्चित कवि लक्ष्मण प्रसाद 'मित्र' इसके उदाहरण हैं। प्रायः समस्त अवधी कविता मर्मजों ने आधुनिक अवधी कविता का विश्लेषण करते हुये कविनाम परिगणन के अंतर्गत मित्र जी का स्मरण पुनः-पुनः किया है, किन्तु डॉ. श्यामसुंदर मित्र 'मधुप' के अतिरिक्त अन्य किसी ने उन्हें सोदाहरण प्रस्तुत नहीं किया है। जिन व्यक्तियों ने अवधी कविता के आधुनिक पक्ष पर शोध कार्य किया है, वे भी इस परिश्रम से मुँह चुरा गये। फलतः आज हमारे अवधी कवियों की एक दीर्घ सूची है, मगर उनके विषय में ठोस ज्ञान का नितान्त अभाव। यह सूचनात्मक ज्ञान प्रतियोगी परीक्षाओं अथवा वाद-विवाद प्रतियोगिताओं में उपयोगी हो सकता है किन्तु शोध के गंभीर क्षेत्र में इस प्रवृत्ति का निषेध होना चाहिए।
1906 ई० में हिंडौरा, जिला सीतापुर में जन्में मित्र जी 02 जनवरी 1989 ई० को दिवंगत हुए। प्रायः 83 वर्ष के जीवन का तीन चैथाई भाग उन्होंने साहित्य सेवा में बिताया। उन्होंने कृषि कार्य और संक्षित्र व्यवसाय करते हुए अपने पारिवारिक-सामाजिक दायित्वों का निर्वाह किया। रचना के प्रति उन्हें अगाध आस्था थी। उन्होंने खड़ी बोली, अवधी, उर्दू और ब्रज में रचनाएँ लिखीं। कुछ रचनाओं के नाम इस प्रकार हैं-

\section{अवधी कविता -}

1. सतनजा 2. अवधी की अठिलान 3. अपनी किंगिरी पर अपन राग 4. परपंचु 5. बरसाती मेंढक आदि।

\section{अवधी गद्य-}

1. सुनीता 2. सुधरि सगाई 3. कोहरे पर की कचैंधनि आदि। 
ब्रज -

सनेह कौ मारगु

उर्दू-

1. सुल्तान नासिरूदीन 2. ताजमहल 3. जहांआरा की मृत्यु शैया 4. शेर अफगन की सदा आदि।

\section{खड़ी बोली कविता-}

1. वाटिका 2. असंतुलित तुला 3. भारतवर्ष गांवों में है 4 . साम्यवाद की ओर 5 . चैपाल आदि।

\section{खड़ी बोली गद्य-}

1. बाणशैया (नाटक) 2. रामरूप 3. चतुरी की चतुराई 4. भक्त वृत्रासुर

स्पष्ट है कि मित्र जी ने अनेक शैलियों-विधाओं और भाव आयामों में अपनी रचना यात्रा की है। किन्तु साहित्य के जनसंकुल पटल पर उन्हें अवधी कवि के रूप में सर्वाधिक और सर्वप्रथम ख्याति प्राप्त हुई है। 1928 ई० से मित्र जी ने अवधी में रचनाएँ प्रारंभ की। 'सुकवि' पत्रिका में मित्र जी की रचनाएँ सम्मान के साथ प्रकाशित होती थीं। इसके अतिरिक्त 'माधुरी', ‘सुधा', 'सूत्रधार', 'राष्ट्र संदेश और 'रसराज' आदि उस युग की प्रतिष्ठित पत्रिकाओं में उन्हें स्थान प्राप्त होता था। यह दुर्भाग्य ही कहा जायेगा कि स्फुट प्रकाशन के अतिरिक्त उनकी अवधी कविताओं का कोई एक स्तरीय संकलन उनके जीवन काल में प्रकाशित नहीं हुआ। 'मैं और मेरे जीवन साथी' संस्मरणात्मक पुस्तक में अत्यंत भावपूर्ण क्षणों में उन्होंने इस विडंबना का उल्लेख किया है। अपनी समस्त अवधी कविताओं को उन्होंने 'सतनजा' शीर्षक से प्रकाशित करने की योजना बनाई थी। इसी पांडुलिपि के आधार पर उन्हें उ०प्र० हिन्दी संस्थान द्वारा 'जायसी पुरस्कार' प्राप्त हुआ था।

मूलतः मित्र जी ग्रामीण व्यवस्था के कवि हैं। उनकी अवधी रचनाओं में उनका जनपद और गांव मुखर होता है। उनमें सामाजिकता और देश प्रेम, प्रकति चित्रण, हास्य व्यंग्य, सांस्कृतिक भावना, वैषम्य की अनुभूति और अंचल अनुराग प्रचुर है। गांव का जीवन उनका भोगा यथार्थ है। प्रखर ग्राम्यानुभूति के सहारे वे यथार्थ को
उसकी गत्यात्मकता में देख सके हैं। किसान जिस शक्ति से प्रेरित होता है, वह उसका घर-परिवार है। प्रकृति से उसका सीधा संपर्क है, वह अपने समस्त अंतर्विरोधों के बावजूद इस देश का प्राण है। गाँव का एक चित्र दर्शनीय है-

बरगद के बिरवा का सुन्दर साम्याना ताना हरा-भरा। त्यहि तर धरती के देउतन का खरू रूपु धरे खरिहानु परा।।

दुई बैल क्यहू के तीनि भये, चारिउ की कहूं मची मड़नी।

कोई भुइं लोटन गुल्ला संग मचियाइसि बधिया जस संड़िनी।

भैसा के साथ बैल का गरू, माची के बीच फंसावा गा। समुझौ अन्तर जाती अमेलु दुई विधि का ब्याह रचावागा।। बहुरिया बड़ेन की दाब गहें, टिकुवा, लिलुवा का हांकि रहीं।

घूंघुट की जार परी मछरी, आँखों आकुल हैं झाँकि रहीं।।1

कृषक के साथी के रूप में मित्र जी ने नारी का अत्यन्त सहज-सार्थक चित्रण किया है। नारी यहाँ वस्तु नहीं सक्रिय नागरिक है। 'बहू को सीख' कविता दृष्टव्य है'

भई भगवान की दाया जो हमारे धाम आई हौ। लच्छिमी रूप हौ, सुख और सम्पति साथ लाई हौ।। सुना है सहर के इस्कूल माँ इलिमौ पढ़ी कुछु, हौ। अंगौछा, बढ़नियाँ, उरमालु काढ़ै माँ कढ़ी कुछु, हौ।। तुमारै आई युहु सब गाइँ गोरू खेतु भुइँ छानी। रही ना बात पर की हतै चुकिउ घर की बहूरानी।। चलाये अब तुमरहे घरू चली यहिमां न बलु जानौ। भरोसा म्वार कौनु बुढ़ानि काया पाक फलु जानौ।। बड़ी, बूढ़ी ज्यटानी सासु की स्यावा किहेउ डटिकै। चल्यौ वह चालु चैचन्दी, बढ़ै मरजाद चैखटिकै।। 
न थौनी गैर की छावौ, न राखौ डाह पर धन की।

मेहरिया घोरि फुसिलैहैं, सुन्यौ सबकी, किहेउ मन की।।

बिलाउज और जम्पर की हियां पहिरे न कीमति है।

किसानन की मड़ैया माँ कमीचन तक गनीमति है।

उजर कपरा है उम्दा मुलु बुरी पोसाख भरकीली।

मिलौ सबते, चलौ ढंग ते, रहौ दीदा कि सरमीली।।

लगी लपटी न बातै, सांचु हैं, जौ ध्यानु दै चलिहौ।

तौ दाना पेट भरि खैहौ, हमेसा फूलिहौ फलिहौ।।

किन्तु पूरा परिवार दिन रात जूझने पर भी अपने लिए संपन्न वर्तमान और सुरक्षित भविष्य नहीं बना पाता है। इसका कारण है, शोषण का भयानक दमनचक्र/शोषण का प्रतिनिधि है भ्रप्ट राजनीति। राजनीति ने व्यक्ति को वोट बना दिया है। गाँव से लेकर दिल्ली तक एक ही भावना व्याप्त है। किसान व्यथित होकर पूँछता है:-

जो तुमका कुछु सुखु पहुँचाइनि, अकि पहुँचाइनि घाट।

आजु तलकु दुख दर्द न पूछिनी, लिहिनि नजरि माँ ल्वाट।।

अब तुमका फुसलावै आये पहिरि कमरकट क्षाट।

राजनीति की गैस उज्यरिया मगन बड़े औ छवाट।।

उलरि-उलरि कै चले बुझावै ई अँखिफ्वरवा ब्वाट।

का सरकार करै कौंसिलि माँ जन खुसामदी भाट।

कौनि लागु है परखैया की अपन दाम जब ख्वाट।

तुमहूँ 'मित्र' बुड़क्की मारौ, तौ जमि जाय ग्वाट।

किसानौ किहिका द्याहौ वाट। ${ }^{3}$

मित्र जी ग्रामीण व्यवस्था के सही व्याख्याता हैं। उनकी रचनाओं में समस्त पर्व और त्यौहार उजागर हुए हैं। दीपावली के दिन किसान अपने जीवनाधार खेत को जगाते हैं। भूमि के प्रति यह श्रद्धा ठोस कारणों पर आधारित है:-

अबकी ब्याह बिटेवा का है,
खेत देवता पार करौ।

भरैं नाज से डेहरी-बखरी,

अब की ऐसी फर निकरौ।।

खात नात पर्जा का खर्चा,

करजा पानी निपटावौ।

बरखा, जाड़, तपन का सेवकु,

अपनि जानि कै अपनावौ॥।

मुरझाये मन का किसान के,

जीवन एकु भरौ ताजा।

मेड़े दिया बारि बिनयिति है,

जागति रह्यो ख्यात राजा। 4

मित्र जी ग्रामीण जीवन में व्याप्त सांस्कृतिक धार्मिक एकता के सूत्र को स्पष्ट करते हैं। वे बताते हैं कि सारा भेदभाव भ्रम है। ऐसे भेद भरने वाले लोगों को कवि धिक्कारता है-

जुम्मन की महजिद मा घुसि कै

ऐसी वैसी ताका।

मउके ते गिरिजाघरू पावा

हिम्मति कइकै झाँका।।

ठाकुर द्वारा और सेवाला

नीकी तना निहारा।

सब मा राम खुदा येसू का,

हिरि, फिरि वहै नजारा।।

ओ पंडित पादरी मोलवी का अस चाही रे।

हमरे मन मा भेदु भरइया तुइ को आही रे। ${ }^{5}$

ऐसे भेद जो लोग उत्पन्न करते हैं, उनका मंतव्य सही बिन्दुओं से संघर्ष को विपथित करना होता है। जो संघर्ष जीवन की न्यूनतम आवश्यकताओं की पूर्ति के लिए 
होना चाहिए, उच्चतर मूल्यों के लिए होना चाहिए। वह राम-रहीम के झगड़े में सिमट जाता है। यह सत्ता का बड़ा पुराना चरित्र है। अवधी कविता में कैंटेसी का पहला प्रयोग करते हुए मित्र जी ने इस तथ्य को स्पष्ट किया है। मित्र जी की 'सपनु द्याखा' कविता उद्धरणीय है-

काकनि हम एक सपनु द्याखा।

कोटिन कंकाल किसानन कै, लाखन मजूर मरहे-झरहे।

कौन्यू विधि तन मां प्रान राखि, लड़ि रहे मौत ते जौ फुरहे।।

जाड़े की उदरी तेज हवा, चिथरन ते जामा झांपि रहे।

बेघर सब बाहर परे-परे द्याखा सरदी मां कांपि रहे।।

यतनिहै बखत माँ राजा की असवारी निकरी धूम किहै,

क्रई साफा, कोई दुपल्ख्वी माँ, कोई खवपरी पर टीम दिहै।।

हमका जिड राखे का नाही, उनका घिव खाति लपन द्याखा।

काकनि हम एकु सपन द्याखा। ${ }^{6}$

मित्र जी ने ग्रामीण प्रकृति के सुन्दर चित्र अपनी रचनाओं में दिये हैं। प्रकृति चित्रण की परंपरा में ये देशज बिम्ब अत्यंत सार्थक हैं। यद्यपि वे बाह्य प्रकृति की अपेक्षा अन्तः प्रकृति के चितेरे अधिक हैं तथापि कुछ चित्र देखने योग्य हैं-

प्रभात का चित्र -

जागरन का जगत मां प्राची सुनहरा थार लाई।

पौन पुरवैय्या प्रभाती मधुर सुरमा गुनगुनाई।।

ताल भीतर कमलिनी मुस्का उठी फिरि खिलखिलाई।

चहक चारिउवारचाहभरी चिरइयन केरि छाई।।

मित्र जी प्रगतिशील चेतना के कवि हैं। उनमें इसीलिए जीवन की गतिशीलता है। बिना किसी वाद में पड़े अपनी सहज-सरल दृष्टि के सहारे वे युग का सत्य अंकित कर देते हैं। बंशीधर शुक्ल, पढ़ीस और मृगेश की परम्परा के वे श्रेष्ठ धारक हैं। पत्रिका 'बिरवा' ने अप्रैल 1989 में 'मित्र विशेषांक' प्रकाशित किया था। उस
विशेषांक के बाद मित्र जी प्रकाश में विशेषतः आये। उन पर शोध और आलोचना का उपक्रम प्रारंभ हुआ है।

निष्कर्ष -

कहने का तात्पर्य यह कि मित्र जी की रचनात्मकता के विवेचन से हम एक अत्यंत समृद्ध रचना संसार को उजागर कर सकते हैं। प्रकाशकीय प्रोत्साहन से जो कुछ कम महत्त्वपूर्ण कवि कवितावतार बन बैठे हैंउनकी तुलना में मित्र जी का महत्व भी तभी प्रतिपादित होगा। 'अवधी कविता का वृहद् इतिहास' लिखने की चुनौती स्वीकारनी होगी। तभी ऐसे अलक्षित-अचर्चित किन्तु साहित्यनिष्ठ रचनाकारों का सार्थक मूल्यांकन संभव है अन्यथा ऐसे रचनाकारों का उपालंभ हमें सुनना पड़ेगा। मित्र जी ने 'किसान' के ब्याज से जो कहा है वह स्मरणीय है-

हमरी भलाई का बहाना कै टिकसकु बाँधयो, आगे ठढ़िहायउ निसान जानि हमका। कुली, कर्मचारी औ मजूरन का मूड़े धर्यो, झूठौ मनु भर्यौ न रिसान जानि हमका। दून भा लगानु जिमींदारी जपि फैदा किह्यौं, माँड्यौ खूब मैदा और पिसान जानि हमका। वाटन कै बखत दुवारू रोजु काँड्यौं अब, छाँड्यौ बीच धार मां, किसान जानि हमका।।

हमारा कर्तव्य है कि ऐसे समर्पित कवियों का उचित समय पर मूल्यांकन करें ताकि उनकी रचनात्मकता का सही सम्मान हो सके।

सन्दर्भ -

1. https://notnul.com/Pages/Preview.aspx? Shortcode=EWSmYgTX

2. बिरवा पत्रिका, अवधी अध्ययन केंद्र, लखनऊ, 1989, पृ. 32

3. वही, पृ. 39

4. वही, पृ. 54

5. वही, पृ. 62 
6. https://notnul.com/Pages/Preview.aspx? Shortcode=EWSmYgTX

7. वही

8. वही

\section{सहायक सन्दर्भ ग्रन्थ -}

- अवधी ग्रन्थावली (खण्ड-4), सम्पादक जगदीश पीयूष, वाणी प्रकाशन, नई दिल्ली, 2011

- अवधी और उसका साहित्य, त्रिलोकी नारायण दीक्षित, सं०-क्षेमचन्द्र 'सुमन', राजकमल प्रकाशन, दिल्ली, 1954

- अवधी साहित्य: सर्वेक्षण और समीक्षा, सं० जगदीश पीयूष, लोक साहित्य संस्थान, इलाहाबाद, 1978 ई०

- अवध-अवधी विविध आयाम, सं०-डॉ. रामशंकर त्रिपाठी, अवधी साहित्य संस्थान, फैजाबाद, 1994

- अवधी कविता के हीरक हस्ताक्षर, सं०-डॉ. रामशंकर त्रिपाठी, अवधी साहित्य संस्थान, फैजाबाद,1993

- समकालीन अवधी कविता, सं० डॉ. राधिका प्रसाद त्रिपाठी, सं० डॉ. रामशंकर त्रिपाठी, अवधी साहित्य संस्थान, फैजाबाद, 1994

- अवधी भाषा एवं साहित्य का इतिहास, राजेन्द्र प्रसाद श्रीवास्तव, भवदीय प्रकाशन, फैजाबाद, 1993

- अवधी भाषा और साहित्य का आलोचनात्मक इतिहास, ज्ञानशंकर पाण्डेय, मीरा प्रकाशन, 1989

- पढ़ीस ग्रन्थावली, सं० रामविलास शर्मा, उ०प्र०हिन्दी संस्थान, लखनऊ, 1998
- आधुनिक हिंदी कविता (प्रतिनिधि चयन: 1850 से अब तक), अमरेन्द्र नाथ त्रिपाठी, राजकमल प्रकाशन, नई दिल्ली, 2000 (पेपर बैक)

- अवधी साहित्य की भूमिका, डॉ. त्रिभुवन नाथ शुक्ला, जयभारती प्रकाशन, इलाहाबाद, 2003

- अवध ज्योति (पत्रिका), सं० डॉ. रामबहादुर मिश्र, अवध भारती संस्थापक, नरौली, बीजापुर (हैदरगढ) बाराबंकी

- अवधी ग्रन्थावली (खण्ड 1), सम्पादक जगदीश पीयूष, वाणी प्रकाशन, नई दिल्ली, 2008

- अवधी ग्रन्थावली (खण्ड 5), सम्पादक जगदीश पीयूष, वाणी प्रकाशन, नई दिल्ली, 2011

- अवधी काव्यधारा, श्यामसुन्दर मिश्र 'मधुप', सुलभ प्रकाशन, लखनऊ, 2002

- लोक साहित्य की भूमिका- डॉ. कृष्णदेव उपाध्याय, लोकभारती प्रकाशन, इलाहाबाद, 2019

- हिन्दी साहित्य कोश, प्रधान सं०- धीरेन्द्र वर्मा, ज्ञानमण्डल लि०, बनारस, 2015

- लोक साहित्य-विधाएं एवं दिशाएं, डॉ. कैलाशचन्द्र अग्रवाल, चिन्मय प्रकाशन, आगरा, 1986

- लोक साहित्य विज्ञान, डॉ. सत्येन्द्र, शिवलाल अग्रवाल एण्ड कं०, आगरा, 1971

- हिन्दी साहित्य का बृहद् इतिहास (प्रथम भाग), सं०-डॉ. राजबली पाण्डेय, नागरी प्रचारिणी सभा, काशी, संवत् 2017

- अवधी लोकगीत विरासत, डॉ. विद्याविन्दु सिंह, ज्ञान विज्ञान एजूकेयर, नई दिल्ली, 2016

- बुन्देलखण्ड में साहित्य की परम्परा (भाग-2), प्रधान सं०- प्रो० सुरेन्द्र दुबे, साक्षी पब्लिशिंग हाउस, नई दिल्ली, 2016

- अवध के अल्हैत (विभिन्न सर्वेक्षण प्रपत्र) 